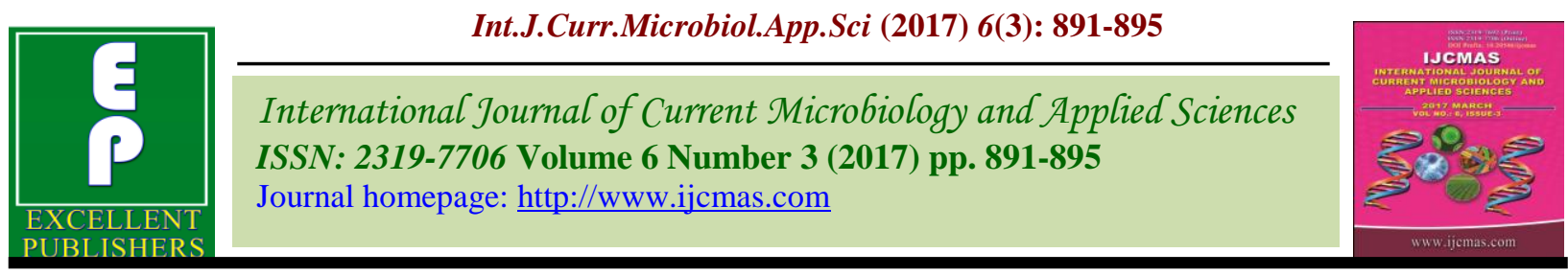

Original Research Article

https://doi.org/10.20546/ijcmas.2017.603.104

\title{
Microbiological Profile and Antimicrobial Sensitivity Pattern of Endotracheal Tube Aspirates of Patients in ICU of a Tertiary Care Hospital in Bhopal, India
}

\author{
Deepti Chandra*, Avinash Laghawe, K. Sadawarte, Tukaram Prabhu \\ Department of Microbiology, People's College of Medical Sciences and \\ Research Centre, Bhopal (M.P), India \\ *Corresponding author
}

\section{A B S T R A C T}

\begin{tabular}{|c|c|}
\hline & \multirow{8}{*}{$\begin{array}{l}\text { Mechanical ventilation is a life-saving procedure, but it is associated with a high risk of } \\
\text { acquiring respiratory infections. Hence to prevent it and initiate empirical antimicrobial } \\
\text { therapy, knowledge of microbial profile and their local antimicrobial sensitivity pattern are } \\
\text { essential. A prospective analytical study of Endotracheal tube (ETT) aspirates of } \\
\text { mechanically ventilated patients in Intensive Care Unit (ICU) was done over a period of } \\
\text { six months (Dec2015-May2016). Endotracheal tube aspirates of patients who had been } \\
\text { incubated for } \geq 48 \text { hrs were processed by standard methods with the aim to identify the } \\
\text { microbiological profile of ETT aspirates and their antibiogram. Out of the } 47 \text { samples, } \\
72.3 \% \text { were culture positive. Gram negative enteric aerobic bacteria were isolated from } \\
\text { most of the patients, most common being Klebsiella species ( } 32.35 \% \text { ), followed by } \\
\text { Acinetobacter and Pseudomonas. Most of the Gram negative isolates were sensitive to } \\
\text { Meropenem, Tigecycline, and Polymixin B but resistant to Penicillin derivatives and } \\
\text { Cephalosporins. Gram positive cocci were mostly sensitive to Penicillin derivatives, } \\
\text { Vancomycin and Clindamycin. Gram negative organisms are predominant isolates of ETT } \\
\text { in our ICU. Hence empirical therapy, based on bacteriological profile and susceptibilities } \\
\text { is essential to prevent poor outcomes in incubated patients. }\end{array}$} \\
\hline Keywords & \\
\hline e & \\
\hline & \\
\hline $\begin{array}{l}\text { Klebsiella, } \\
\text { Acinetobacter. }\end{array}$ & \\
\hline Article Info & \\
\hline $\begin{array}{l}\text { Accepted: } \\
\text { 18 Februarv } 2017\end{array}$ & \\
\hline & \\
\hline
\end{tabular}

\section{Introduction}

Mechanical ventilation is a life-saving procedure for many patients in Intensive care unit, but it is associated with a high risk of acquiring respiratory infections and a high morbidity and mortality in critically ill patients. The etiologic agents may vary according to the population of patients in ICU, type of ICU-whether Medical ICU, Surgical ICU, or Paediatric ICU, pre-existing illness and prior antimicrobial therapy (Sanjai et al., 2001).

Hence to prevent respiratory infections and initiate empirical antimicrobial therapy, knowledge of microbial profile and their local antimicrobial sensitivity pattern are essential and therefore this study was undertaken.

The main of this study, to identify the microbiological profile of ETT secretions and to study their antimicrobial sensitivity pattern

\section{Inclusion criteria}

ETT tips and aspirates of all patients who had been mechanically ventilated for $>48 \mathrm{hrs}$ for various reasons. 


\section{Exclusion criteria}

ETT aspirates of Post-op ventilated patients and from patients who had been ventilated for $<48 \mathrm{hrs}$.

\section{Materials and Methods}

A prospective observational and analytical study of endotracheal tube secretions of mechanically ventilated patients in ICU was done over a period of six months (Dec2015May2016). All endotracheal tube secretions which were obtained from patients after at least $48 \mathrm{hrs}$ of intubation were processed (Standard Operative Procedures Bacteriology, 2015). The suction catheter tip and the secretions both were subjected to Gram's stain and culture by standard protocols. The positive culture samples were identified by standard biochemical reactions and subjected to antimicrobial susceptibility testing by Kirby Bauer Disc Diffusion method as per standard CLSI guidelines (Clinical and Laboratory Standards Institute, 2014).

\section{Results and Discussion}

A total of 47 samples were obtained during the study period. Among them, 28 (59.57\%) were males and 19(40.42\%) females and 40 were adults and 7 were children. 32 samples (68\%) were from Medical ICU, 8 (17\%) from Surgical ICU and 7 (14.89\%) from Paediatric ICU. Growth was observed in $34(72.3 \%)$ samples, while $13(27.7 \%)$ samples showed commensal flora of the respiratory tract or no growth (Fig. 1).

Gram negative enteric aerobic bacteria were isolated from most of the patients. The most common being Klebsiella species in $11(32.35 \%)$, followed by Acinetobacter in $7(20.58 \%)$ Pseudomonas in 5(14.70\%), Staphylococcus aureus in $3(8.82 \%)$, Citrobacter spp in $3(8.82 \%)$ E. coli in 3
(8.82\%), Coagulase Negative Staphylococcus (CONS) in 1 (2.94\%) Enterococcus in 1 (2.94\%). Most of the Enterobacteriaceae isolates were sensitive to Meropenem, Colistin and Polymixin B but resistant to Ampicillin, Amoxyclav, most of the Cephalosporins and Aminoglycosides. Gram positive cocci were mostly sensitive to Penicillin derivatives, Vancomycin and Clindamycin.

Endotracheal intubation and mechanical ventilation are life-saving procedures needed in clinical conditions like sepsis, acute respiratory distress syndrome and neurological dysfunctions. While mechanical ventilation helps to prevent deaths due to respiratory failure, it poses great threat, by leading to life threatening lung infections by itself According to a recent review by Morehead et al., (2000) the incidence of ventilator associated pneumonia was 9 to $24 \%$ for patients incubated longer than $48 \mathrm{hrs}$.

Culture positivity was more common in elderly male patients who were smokers, and who were admitted for respiratory causes or patients who had pre-existing lung diseases. This is in coherence with the study by Ferrer et al., (2005). No growth or commensals were obtained in predominantly female and paediatric patients and patients ventilated for causes other than respiratory.

In this study Gram negative enteric bacteria were the most common isolates. The most common being Klebsiella species, followed by Acinetobacter and Pseudomonas. Summaiya et al., (2012) found that most common organisms isolated in ETT which produce strong biofilm are Pseudomonas aeruginosa and Acinetobacter spp. Trilok Patil et al., (2014) in their study noted that Pseudomonas aeruginosa was the most commonly isolated organism, followed by Klebsiella pneumoniae. In another study by 
George et al., (2010) Acinetobacter was the most common isolate $(37.5 \%)$, followed by Pseudomonas $(21.8 \%)$ and Klebsiella
(15.6\%). amikacin, gatifloxacin and imipenem were the common sensitive antibiotics in their study (Fig. 2).

Table.1 Antimicrobial susceptibility pattern of Gram negative bacteria:

(\% of susceptible isolates)

\begin{tabular}{|l|l|l|l|l|l|l|}
\hline $\begin{array}{l}\text { SI. } \\
\text { No. }\end{array}$ & $\begin{array}{l}\text { Antibiotics/ } \\
\text { Organism }\end{array}$ & $\begin{array}{l}\text { Klebsiella } \\
\mathbf{n = 1 1}\end{array}$ & $\begin{array}{l}\text { Acinetobacter } \\
\mathbf{n = 7}\end{array}$ & $\begin{array}{l}\text { Pseudomonas } \\
\mathbf{n = 5}\end{array}$ & $\begin{array}{l}\text { E. coli } \\
\mathbf{n = 3}\end{array}$ & $\begin{array}{l}\text { Citrobacter } \\
\mathbf{n = 3}\end{array}$ \\
\hline 1 & Ampicillin & 18.18 & 14.28 & 00.00 & 33.33 & 33.33 \\
\hline 2 & Amoxyclav & 27.27 & 28.57 & 20.00 & 66.66 & 66.66 \\
\hline 3 & Amikacin & 27.27 & 28.57 & 60.00 & 66.66 & 66.66 \\
\hline 4 & Ceftriaxone & 9.09 & 14.28 & 00.00 & 00.00 & 33.33 \\
\hline 5 & Cotrimoxazole & 9.09 & 00.00 & 00.00 & 33.33 & 66.66 \\
\hline 6 & Cefixime & 00.00 & 00.00 & 00.00 & 00.00 & 33.33 \\
\hline 7 & Ceftazidime & 18.18 & 14.28 & 20.00 & 33.33 & 33.33 \\
\hline 8 & $\begin{array}{l}\text { Ceftazidime- } \\
\text { Clavulanic acid }\end{array}$ & 54.54 & 42.85 & 80.00 & 66.66 & 66.66 \\
\hline 9 & Levofloxacin & 54.54 & 28.57 & 40.00 & 33.33 & 66.66 \\
\hline 10 & Meropenem & 90.90 & 71.42 & 80.00 & 66.66 & 100 \\
\hline 11 & Colistin & 100 & 85.71 & 100 & 100 & 100 \\
\hline 12 & Polymixin B & 100 & 100 & 100 & 100 & 100 \\
\hline
\end{tabular}

Fig.1

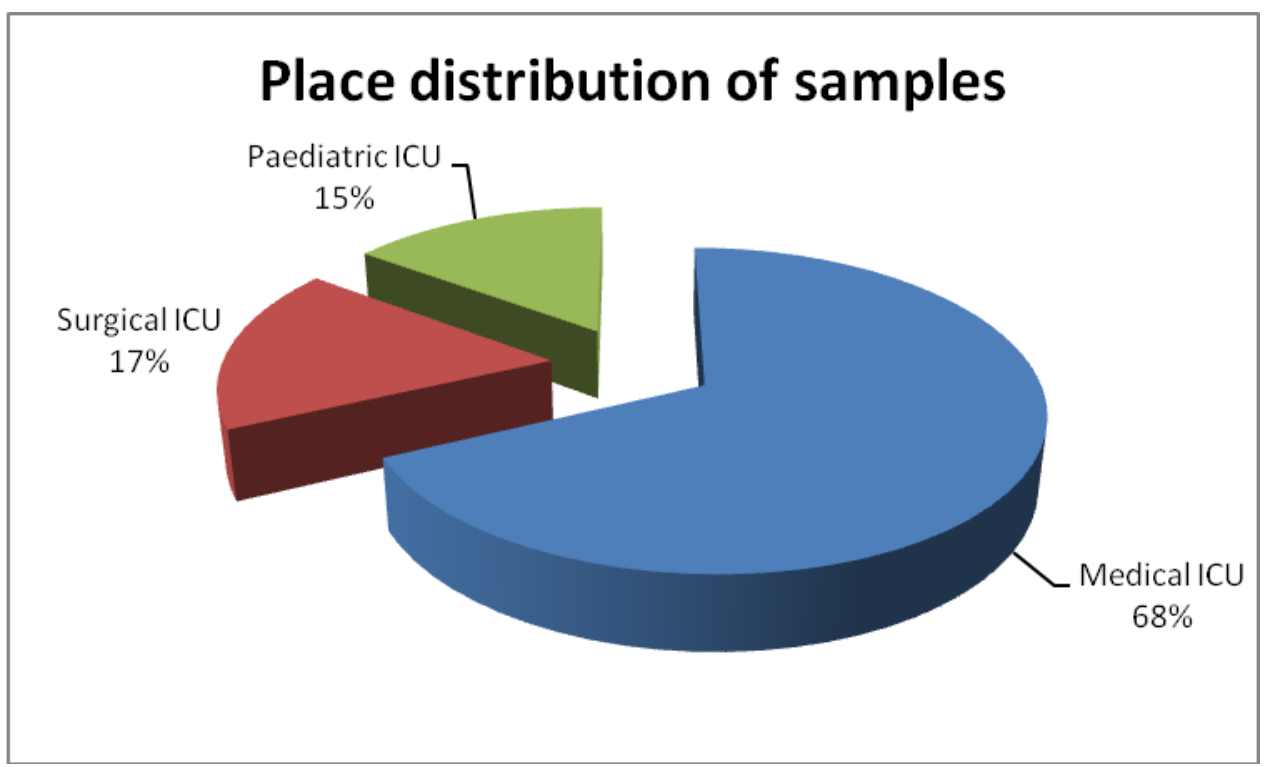


Fig.2

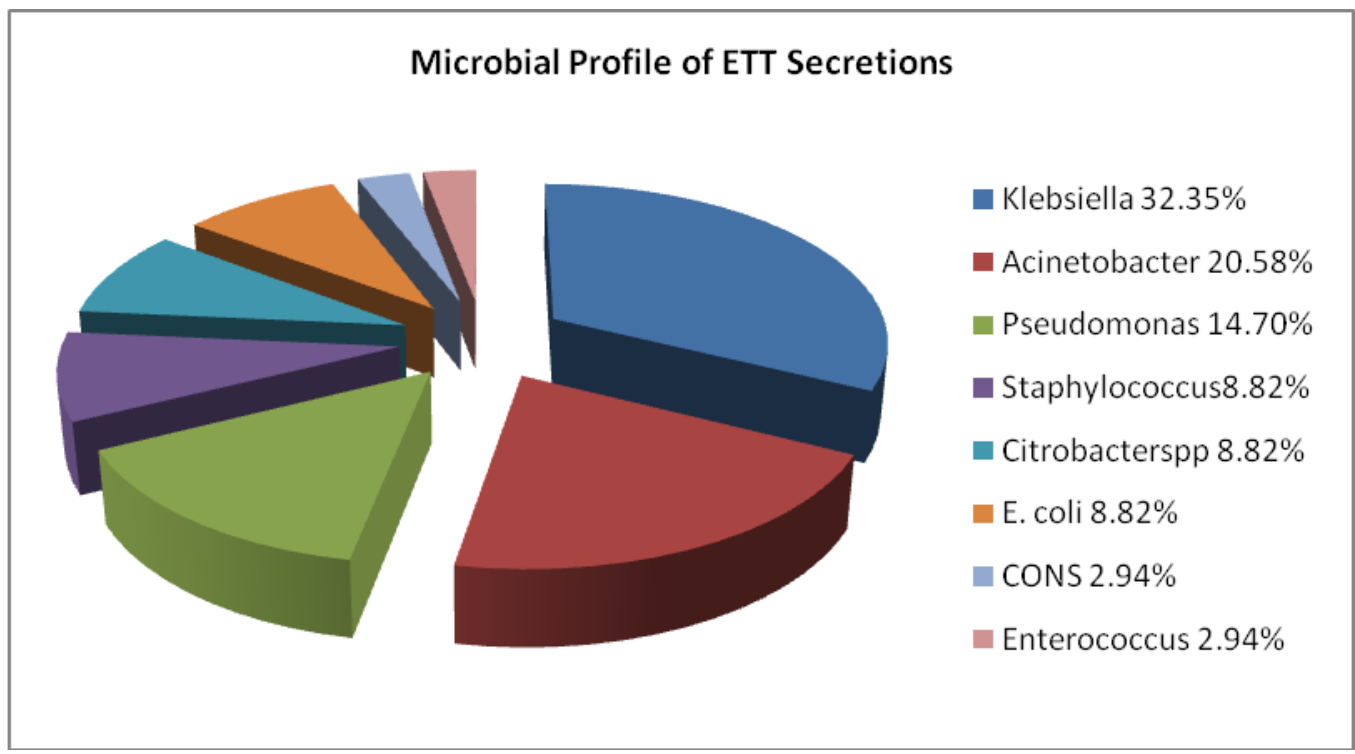

The findings of the present study are consistent with the above studies, except for the antimicrobial sensitivities where most of the Gram negative isolates are resistant to ampicillin, cotrimoxazole, amoxyclav, cephalosporins. A significant number of Acinetobacter and Pseudomonas isolates are also resistant to fluoroquinolones and aminoglycosides. Most of the isolates are sensitive to meropenem but approximately $20 \%$ of the isolates are resistant to meropenem also, which is an alarming trend. Resistance to beta lactam class of antibiotic is a common occurrence and pan-drug-resistant strains are beginning to emerge. Evolutionary stress such as exposure to antibiotics, bacterial gene transfer is responsible for antibiotic resistant trait (Kumar et al., 2011).

In conclusion, gram negative organisms belonging to family Enterobacteriaceae susceptible mostly to carbapenems, colistin and polymyxin antibiotics form the predominant isolates of ETT aspirates in our critical care setup (Table 1). They are mostly resistant to penicillin derivatives, cephalosporins and aminoglycosides. The risk of acquiring infection is higher in patients with pre-existing lung diseases. With an empirical antibiotic regimen we can prevent many instances of ventilator associated pneumonias. Thus the microbiological profile and sensitivity pattern of our ICU shall help in framing the appropriate institutional antibiotic policy for better outcomes.

\section{References}

Cinical and Laboratory Standards Institute. 2014. Performance Standards for Antimicrobial Susceptibility Testing; $17^{\text {th }}$ informational supplement. CLSI document M100-S17(ISBN 1- 56238625-5) Clinical and Laboratory Standards Institute USA.

Drakulovic, M.B., Bauer, S., Torres, A., J.G., M.J.R., J.A. 2001. Initial bacterial colonization in patients admitted to a respiratory intensive care unit: bacteriological pattern and risk factors. Respiration, 68: 58- 66. [Pub Med: 11223732].

Ferrer, M., Ioanas, M., Arancibia, F., Marco, M.A., de la Bellacasa, J.P., Torres, A. 2005. Microbial airway colonization is associated with noninvasive ventilation 
failure in exacerbation of chronic obstructive pulmonary disease. Crit. Care Med., 33: 2003-2009. [Pub Med: 16148472].

George, P., Sequiera, A. 2010. Antimicrobial sensitivity pattern among organisms isolated from the endotracheal aspirates of patients with ventilator associated pneumonia. J. Clin. Diag. Res., 4: 33973401.

Kumar, A.V., Pillai, V.S., Dinesh, K.R., Karim, S. 2011. The phenotypic detection of Carbapenemase in meropenem resistant Acinetobacter calcoaceticus baumannii complex in a tertiary care hospital in south India. $J$. Clin. Diag. Res., 5: 223-6.

Morehead, R.S., and S.J. Pinto. 2000. Ventilator associated pneumonia. Arch. Intern. Med., 160: 1926-1936.
Patil, T. The Study of the organisms colonising trachea in mechanically ventilated patients admitted in the intensive care unit (ICU). International J. Med. Sci. Education, 1(1): 6.

Sanjai, N., Paul, B., Stephen, B., Michael, D., Mark, L., Gary, D. 2001. Sampling variability in the microbiological evaluation of expectorated sputa and endotracheal aspirates. J. Clin. Microbiol., 39: 2344-7.

Standard Operative Procedures Bacteriology. 2015. Antimicrobial Resistance Surveillance and Research Network, ICMR, New Delhi India p37

Summaiya, M. and Urmi, J. 2012. Assessment of biofilm formation by the causative organisms of ventilator associated pneumonia at intensive care unit of a tertiary care hospital. Nat. J. Med. Res., 2(1): 15 .

\section{How to cite this article:}

Deepti Chandra, Avinash Laghawe, K. Sadawarte, Tukaram Prabhu. 2017. Microbiological Profile and Antimicrobial Sensitivity Pattern of Endotracheal Tube Aspirates of Patients in ICU of a Tertiary Care Hospital in Bhopal. Int.J.Curr.Microbiol.App.Sci. 6(3): 891-895.

doi: https://doi.org/10.20546/ijcmas.2017.603.104 